\title{
Notes
}

\section{Combatting food insecurity and rural poverty through enhancing small-scale family farming in the Near East and North Africa}

\author{
Alfredo Impiglia \\ Regional Initiative Manager, FAO Near East and North Africa Office, Cairo \\ Phoebe Lewis \\ Agricultural Officer, FAO Near East and North Africa Office, Cairo
}

\section{The challenge}

The Near East North Africa (NENA) region is exposed to a series of interconnected challenges that impede agriculture and therefore food security and poverty reduction. The economic growth rate in the NENA region has stagnated at two percent per year since 1990. Meanwhile, unemployment rates remain high, especially amongst youth with 28.2 percent unemployment in the Middle East and 30.5 percent in North Africa. These trends present challenges for the region, especially given its high population growth rate, which is above the global average, at 2 percent per year compared with 1.2 percent globally. While the population is growing, the unemployment rates suggest that the transition towards inclusive economic growth has not taken hold.

Around 43 percent of the NENA region's population live in rural areas, which in turn are highly affected by the poverty that results from exclusion from the region's economic growth; 70 percent of the region's poor currently live in rural areas and are largely dependent on agriculture for their livelihoods. Many of these are small-scale family farmers. The region, in turn, is even more dependent on small-scale farmers who generate 80 percent of the region's agricultural production. They are therefore essential to NENA's pathway out of food insecurity and poverty.

\section{The response}

To address these interconnected challenges, the Food and Agriculture Organization of the United Nations developed three Regional Initiatives that reflect the common priorities expressed by the member states of the NENA region. These initiatives are based on the 
principles of country ownership, participation and partnership, and focus on (1) water scarcity, (2) building resilience for food security and nutrition, and (3) empowering small-scale family farmers.

Through the third initiative, FAO is able to work closely with thousands of small-sale farmers and producers in the region. Special attention is paid to women farmers, women agricultural workers and youth involved in agriculture, reflecting the local context, social vulnerabilities and disadvantaging factors. This initiative aims to put farmers and smallholders - as well as their organizations - at the centre of the fight against hunger and poverty through the intensification of their production in a sustainable manner, the strengthening of their capacity of knowledge-based decision making, and a better access to social protection.

\section{Defining small-scale family farmers}

It is important to understand who these farmers are. There is no universally or even regionally agreed upon definition of small-scale farmers. There is, nevertheless, some common characterisations of these farmers based on a technical dimension, property dimension and labour characterisation. The technical dimension focuses primarily on the agricultural components, namely production, output and intermediate consumption level. In addition to this characterization according to agricultural produce, there is a need to characterize the properties of these farmers. It is here that the characterisation of "small-scale" becomes important as the size of the production system is often noted regarding, for example, utilised agricultural area (UAA), turnover and standard gross production. Countries in the NENA region have different definitions and thresholds for holding size. For instance, these are absent in Mauritania and Sudan or relative in Egypt where small-scale family farming is based on land of less than three feddans (i.e. 0.42 hectares). Morocco further differentiates based on rain-fed versus irrigated systems and Tunisia distinguishes based on land potential, income and investment capacity.

Furthermore, to examine the agricultural production, productivity and property type of these farmers alone is insufficient, because the small size of their holdings necessitates a diversification of these farmers' incomes to survive. Therefore, a characterisation of labour needs to include additional off-farm (or off-system in the case of pastoralists) livelihoods such as the sale of labour in neighbouring farms or towns, processing of farm produce, handicraft production, and pendular, cyclical or longer-term migration. Labour productivity and autonomy and dependency relations inside and outside the farm holdings, including gender and/or intergenerational relations, is also important. A final element - and a key reason why examining the impacts on small-scale farmers is so crucial - is that this group is commonly one of the poorest in the NENA countries. Therefore, there is no regional definition of small-scale farmers, and there will be variation in the farmers included from one farming system to another and between countries in this report. Nevertheless, the definition will coalesce around those farmers that are characteristically at or below the poverty line, that are operating on holdings that are used for subsistence or informal business, and in which the farmers typically undertake multiple activities both on and off-farm. 


\section{Trends}

A country or region's agricultural development is closely related to major population trends as well as to structural changes in the economy and the place of agriculture therein as well as to external economic balances. In this context, there are a number of trends influencing these farmers. A major one of which is urbanization, which may be an opportunity as it monetizes food demand. The ability therefore of smaller family holdings to take advantage of this development depends partly on their collective organization as well as on public investments. The trends of collective organization - in the form of producers' organizations and cooperatives varies greatly throughout the region and is generally less mainstreamed than in other regions such as Latin America.

In addition, one of the most significant trends influencing small-scale family farming and agriculture in the region is the arrival of youth onto the labour market. Youth unemployment is extremely high in the region, which means the issue of decent employment and access to social protection must be considered as a government priority.

Agriculture can contribute to this through a stronger coherence between government policies in support of family farming. However, this must be considered in the broader demographic context of the region. Many of these young people are migrating from rural to urban centres in search of better opportunities. This not only puts a pressure on the urban spaces that are not prepared to accommodate them, but also affects the social structure of the rural areas. The elderly and women are assuming a greater proportion of the agriculture work. This can present challenges when you consider that in many ways these women rarely have the same access to resources and power that their male counterparts enjoy.

It is interesting to note that climate change also enters into the picture here. The effects of climate change are and will continue to alter agriculturally-productive zones. For many of these farmers who are already living on the margins of productivity, this could incentivise them to diversify their livelihoods or leave agriculture altogether. In so doing, they contribute to the shifting demographic trend. Not only this, but their exit from agriculture will have implications for the food security of the region, given their contribution to domestic agricultural production. This trend seems likely to increase the region's food import dependence, which is already very high.

\section{Policies and Recommendations}

There are evidently a number of trends that influence and are influenced by these farmers, which centre on poverty reduction and food security. Indeed, after the food crisis of 20072008, there has been a renewed, global interest in the agricultural sector. Nevertheless, the produce of this renewed enthusiasm has largely resulted in investments and political attention towards large-scale capitalistic agriculture. The NENA region is no exception to this trend. There is a lack of knowledge and limited interest in small-scale family farming and that it is poorly supported, except in some few countries where it is addressed from a rural poverty reduction perspective. This is the case in Morocco and somewhat in Egypt and Tunisia. Where specific policies are designed, concrete implementation is often problematic due to a lack of resources on the ground. New policies need to assess where it is pro- 
ductive for small-scale family farming to continue. In these cases, support to ensure their agricultural and labour production and productivity are key. In places where it may not be productive, support to foster sustainable livelihood diversification is becoming necessary. In all cases, the farmers need to be supported in the broader social context through social protection measures that ensure that an enabling environment for their well-being and productivity is created and maintained. To achieve this, the Regional Initiative on Small-Scale Family Farming coalesces its work around three key pillars:

1. Sustainable and innovative practices developed to boost the agricultural productivity of farmers and their associations in small scale family farming.

2. Decent rural employment opportunities and social protection mechanisms for smallscale family farmers developed and incentivised.

3. Rural organizations' and institutions' capacities strengthened to improve small-scale family farmers' access to rural services and markets. 